\title{
Spontaneous cerebrospinal fluid leak from an anomalous thoracic nerve root: case report
}

\author{
Alejandro J. Lopez, BS, ${ }^{1}$ Robert K. Campbell, BA, ${ }^{1}$ Omar Arnaout, MD, ${ }^{1}$ Yvonne M. Curran, MD, ${ }^{2}$ \\ Ali Shaibani, MD, ${ }^{3}$ and Nader S. Dahdaleh, MD ${ }^{1}$ \\ Departments of ${ }^{1}$ Neurological Surgery, ${ }^{2}$ Neurology, and ${ }^{3}$ Radiology, Feinberg School of Medicine, Northwestern University, \\ Chicago, Illinois
}

\begin{abstract}
The authors report the case of a 28 -year-old woman with a spontaneous cerebrospinal fluid leak from the sleeve of a redundant thoracic nerve root. She presented with postural headaches and orthostatic symptoms indicative of intracranial hypotension. CT myelography revealed that the lesion was located at the T-11 nerve root. After failure of conservative management, including blood patches and thrombin glue injections, the patient was successfully treated with surgical decompression and ligation of the duplicate nerve, resulting in full resolution of her orthostatic symptoms.
\end{abstract}

http://thejns.org/doi/abs/10.3171/2016.4.SPINE151465

KEY WORDS cerebrospinal fluid; leak; anomalous; dura; spine; congenital; thoracic nerve root

$\mathrm{S}$ PONTANEOUS intracranial hypotension most commonly affects adults and is more often encountered in women than in men. $2,7,10,18,19,22,23,25$ Postural headache is frequently the only reproducible clinical symptom; however, associated nausea, vomiting, abducens nerve paresis, tinnitus, hyperacusis, and visual field defects have been reported. ${ }^{19,25}$

Cerebrospinal fluid (CSF) leaks underlie the majority of cases of spontaneous intracranial hypotension and may occur throughout the spine, with a predilection for the cervicothoracic junction and thoracic regions. ${ }^{19}$ Spontaneous CSF leaks have been associated with connective tissue disorders, ${ }^{19,21,22}$ leading to hypotheses that meningeal fragility results in dural perforation or the formation of diverticula following minor trauma. ${ }^{1,6,11,14,20}$ In untreated CSF leaks, the postural component of the headache may abate with chronicity; thus, undiagnosed CSF leaks may prove an occult cause of otherwise idiopathic headache..$^{11,19}$

Spinal nerve root anomalies are rare but well-characterized entities in the lumbosacral spine. Anomalies have not been reported in the thoracic spine and have not been associated with CSF leaks. The authors present a unique case of intracranial hypotension secondary to a CSF leak at a congenital thoracic nerve root anomaly.

\section{Case Report}

History and Examination

A 28-year-old woman presented complaining of po- sitional occipital headaches associated with tinnitus and nonspecific visual changes for 4 months with no history of recent trauma. Her symptoms were relieved in recumbence. No other neurological deficits were appreciated.

Imaging

MRI of the brain revealed leptomeningeal enhancement (Fig. 1), indicative of intracranial hypotension. The patient underwent CT myelography, which demonstrated extrathecal contrast with suspicion of a CSF leak at the left T-11 nerve root sleeve (Fig. 2).

\section{Treatment}

Nonspecific lumbar blood patches, lesion-directed blood patches, and thrombin glue injections provided temporary improvement, but all subsequently resulted in full return of symptoms. After failure of conservative therapies, surgical exploration by left foraminotomy was performed. A redundant left T-11 nerve root (Neidre and Macnab classification Type $2 \mathrm{~A}^{13}$ ) was discovered, focally leaking CSF from the axilla. The nerves were then ligated proximal to the defect and a lumbar drain was placed (Fig. 3).

\section{Postoperative Course}

The patient was kept supine with flat bed parameters with a lumbar drain for CSF drainage (10-15 $\mathrm{ml} / \mathrm{hr}$ ) for 1 week postoperatively. She experienced complete reso-

ABBREVIATIONS CSF $=$ cerebrospinal fluid. 


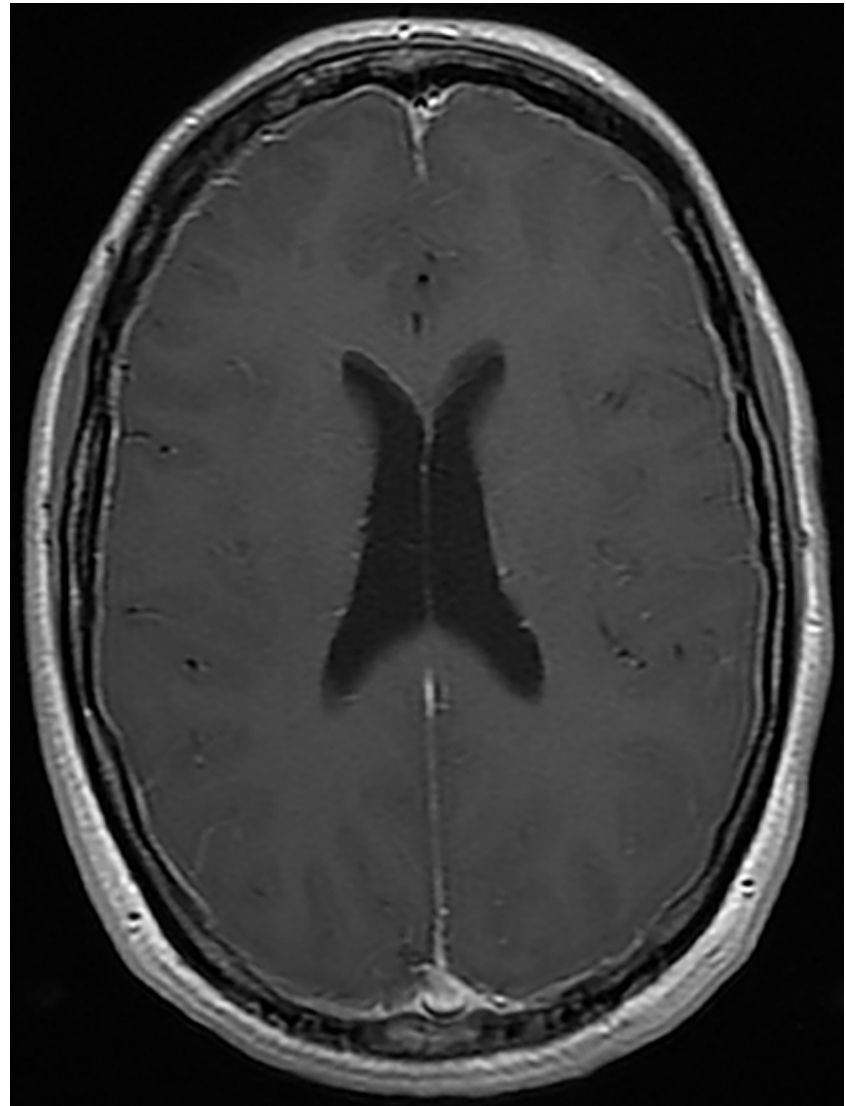

FIG. 1. Axial contrast-enhanced T1-weighted MR image of the brain revealing diffuse leptomeningeal enhancement.

lution of her positional symptoms with residual nonpositional headaches of significantly reduced intensity. CT myelography was subsequently performed to evaluate the continued headaches and revealed no detectable CSF leak (Fig. 4). MRI of the brain also revealed resolution of leptomeningeal enhancement (Fig. 5). At the 1-year followup visit, the patient reported resolution of all orthostatic symptoms.

\section{Discussion}

Spontaneous CSF leaks have been associated with connective tissue diseases including polycystic kidney disease, Marfan and Ehlers-Danlos syndromes..$^{19,21,22}$ The patient had no diagnosis of connective tissue disease at the time of presentation. The leak was discovered at the axilla of a nerve root redundancy-suggesting an anatomical or mechanical etiology. As such, we hypothesize that the anomalous nerve root contributed to the failure of the dura. This represents a rare and unusual etiology of a CSF leak that has not previously been described in the literature.

An embryological explanation for congenital nerve root anomalies in humans has not been fully elucidated; however, animal studies implicate errors in axon guidance. The process of an axon finding and attaching to its target muscle group relies on a complex series of chemical gradients and receptor modulation. ${ }^{16} \mathrm{~A}$ dose-dependent

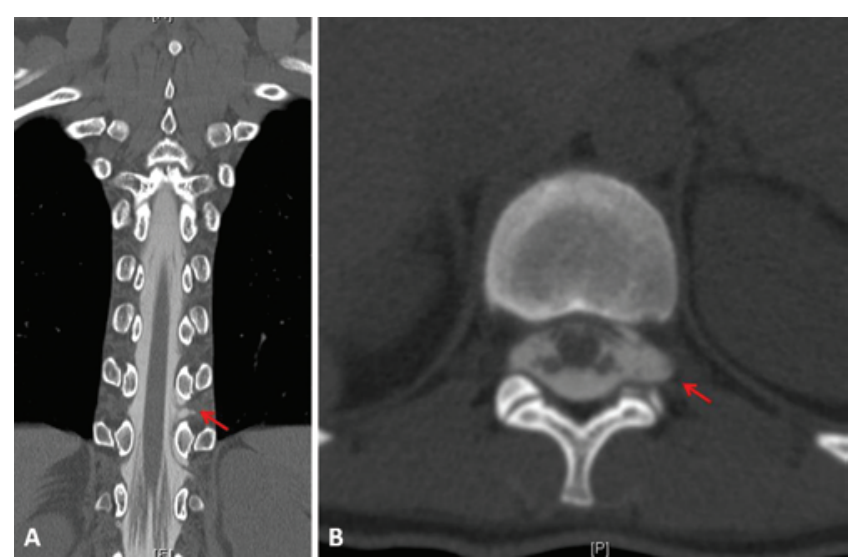

FIG. 2. Coronal (A) and axial (B) CT myelograms revealing evidence of CSF extravasation at the level of the left T-11 nerve root sleeve (arrows). Figure is available in color online only.

increase in spinal nerve-to-muscle mismatch (which produced aberrant nerve root anatomy) has been demonstrated in Class III semaphorin-deficient chick embryos. ${ }^{12,16,17}$

Spinal nerve root anomalies in humans are well described in the lumbosacral spine but not in the thoracic spine. Lumbosacral anomalies have been reported to occur in $8.5 \%$ to $30 \%{ }^{4}$ of autopsy specimens. Clinically, these have been largely implicated in the study of degenerative conditions of the spine due to the atypical nerve conformation occupying a larger portion of the intervertebral foramen and also for placing the surgical patient at an increased risk of iatrogenic injury during decompression. ${ }^{3}$

In a study of 46 cases, Postacchini et al..$^{15}$ found that $21 \%$ of patients with an anomalous nerve root exhibited concomitant lumbosacral bony abnormality, including lumbarization of S-1, sacralization of L-5, and a case of congenital absence of the facet nearest the anomaly. $\mathrm{Pa}$ tients with lumbosacral nerve root anomalies presented with radicular symptoms if they had any symptoms due to these lesions. No patients were reported to have symptoms of a dural leak. While nerve root anomalies have not been associated with congenital defects in the dura, the paucity of available evidence allows for either a congenital or a mechanical etiology of our patient's leak. We posit 2 hypotheses: 1) that the dura was weakened by the bifurcation of the nerve root or 2) that repeated microtrauma between the redundant roots within a stenotic foramen eroded the dura. A tethering effect on a single nerve root in an anomalous pair has been described as a cause of radicular pain ${ }^{5}$ and may also explain undue tension at the axilla of the anomaly.

Definitive diagnosis and localization of a CSF leak may be achieved using a variety of imaging techniques, including CT myelography, MR myelography, and radioisotope cisternography. Of these 3 techniques, CT myelography has been found to be the most effective at identifying the defect. ${ }^{19,21}$ In our patient, CT myelography localized the leak but was unable to identify the nerve anomaly. These findings are concordant with a study by Haijiao et al., which showed MRI to be superior for diagnosing nerve anomalies.

Surgery to repair a CSF leak is reserved for patients 

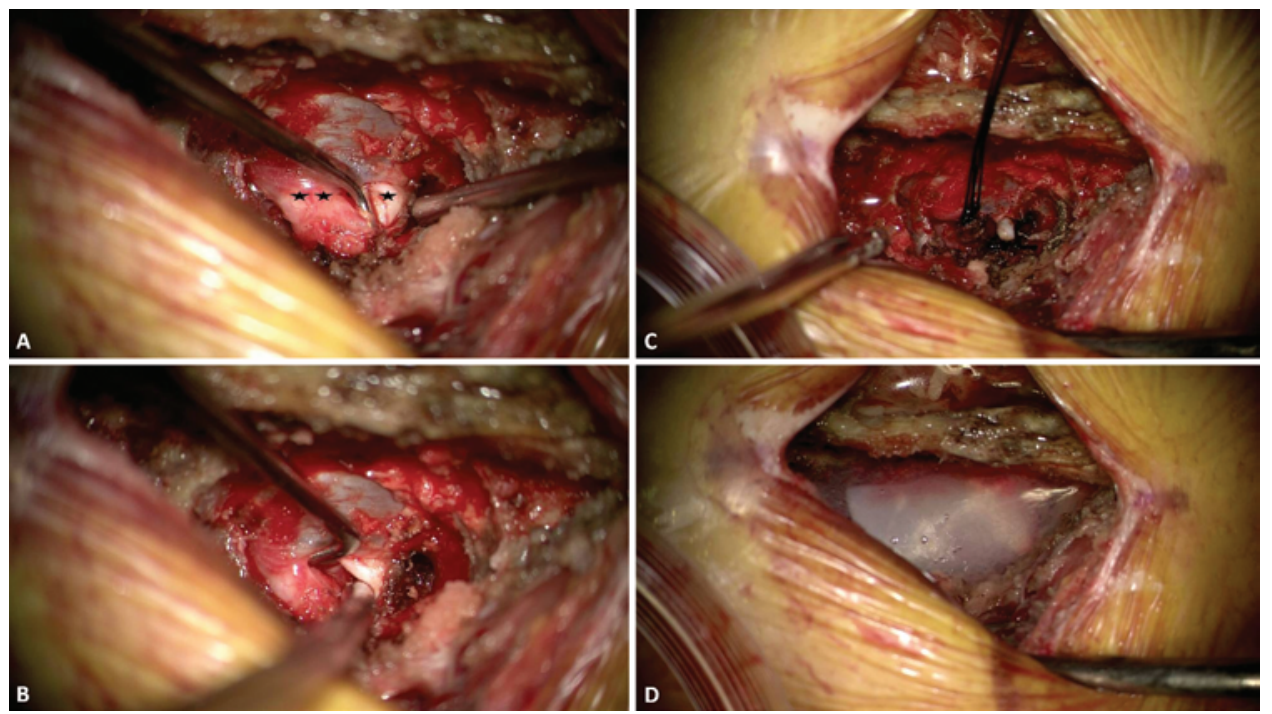

FIG. 3. Intraoperative image of duplicate T-11 nerve roots (A) (double asterisks and single asterisk). There was evidence of CSF leakage at the level of the axilla between the duplicate nerve roots (B). The nerve roots were ligated $(\mathbf{C})$ and then cut. A piece of dural substitute was then placed ventral and lateral to the spinal cord, and then a dural adhesive was placed to complete the duraplasty (D). Figure is available in color online only.

who have not obtained satisfactory relief with more conservative management and have an identifiable anatomical abnormality on imaging studies. Diverticula are ligated and dural tears are repaired in the fashion most customary to the surgeon. Outcomes have been found to be positive with few complications. ${ }^{20-22,24}$ In our patient, posterior exposure of the thoracic nerve root allowed for ligation of the entire nerve root, leading to complete and lasting resolution of orthostatic symptoms. The headaches that persisted in the subacute postoperative period are likely unrelated to the CSF leak, as they were nonpositional, decreased in severity, and were of different quality from her presenting complaint.

\section{Conclusions}

Thoracic nerve root redundancy may represent an undiagnosed etiology of spontaneous CSF leak. CT my-
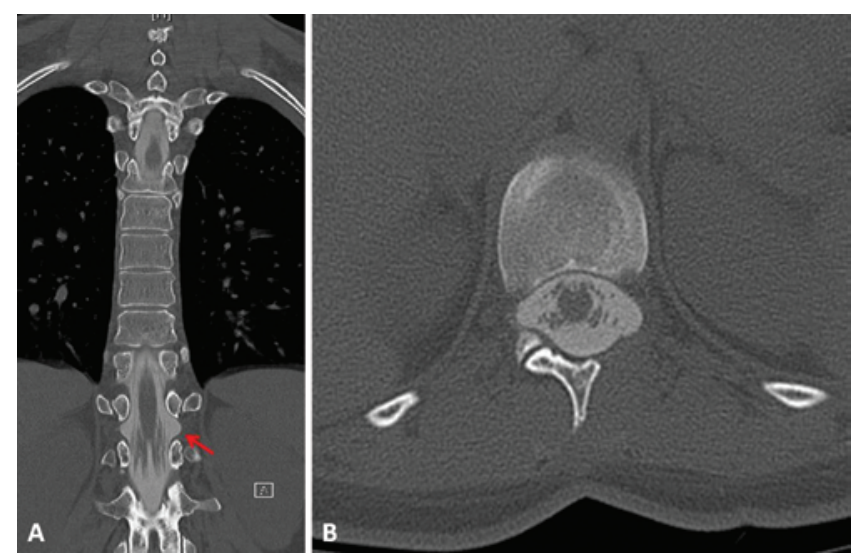

FIG. 4. Postoperative coronal (A) and axial (B) CT myelograms revealing the resolution of the CSF leak at the level of the nerve sleeve (arrow). Figure is available in color online only. elography is insufficient for visualizing these anatomical anomalies. Treatment with surgical ligation proved a viable option for management when conservative measures failed.

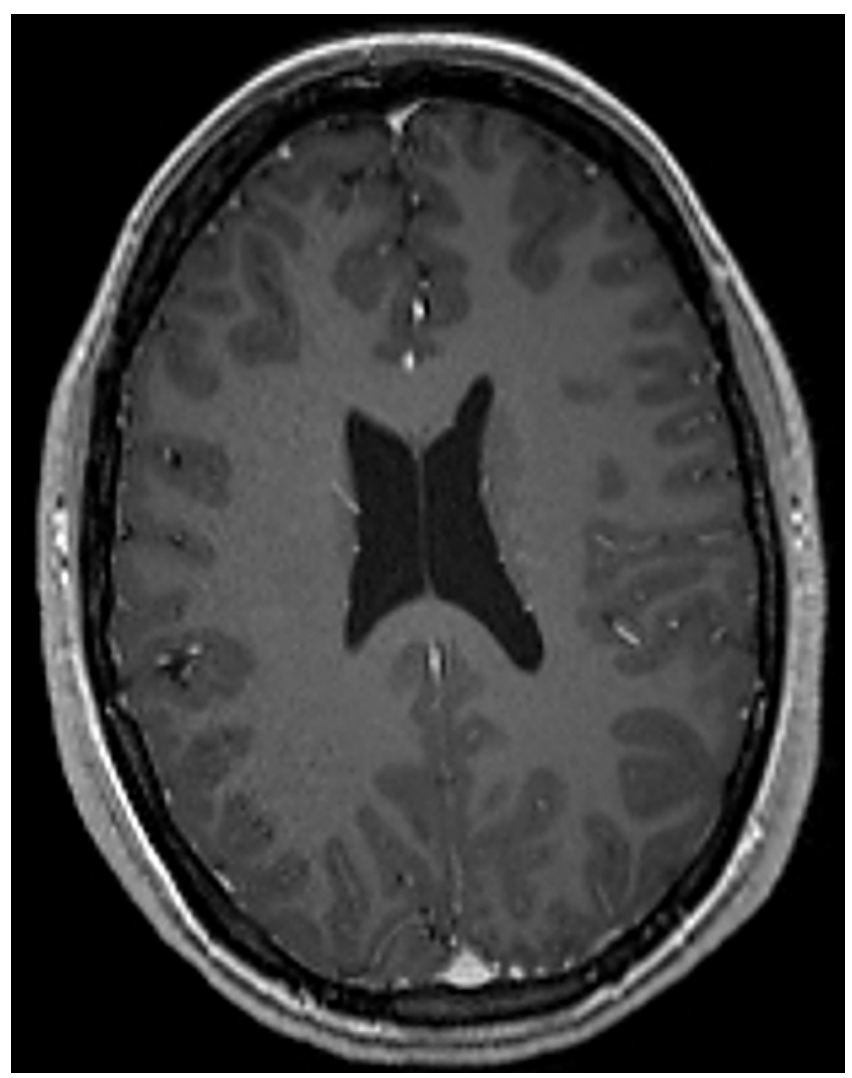

FIG. 5. Postoperative axial contrast-enhanced T1-weighted MR image of the brain showing resolution of the leptomeningeal enhancement. 


\section{References}

1. Bell WE, Joynt RJ, Sahs AL: Low spinal fluid pressure syndromes. Neurology 10:512-521, 1960

2. Benzon HT, Nemickas R, Molloy RE, Ahmad S, Melen O, Cohen B: Lumbar and thoracic epidural blood injections to treat spontaneous intracranial hypotension. Anesthesiology 85:920-922, 1996

3. Burke SM, Safain MG, Kryzanski J, Riesenburger RI: Nerve root anomalies: implications for transforaminal lumbar interbody fusion surgery and a review of the Neidre and Macnab classification system. Neurosurg Focus 35(2):E9, 2013

4. Chotigavanich C, Sawangnatra S: Anomalies of the lumbosacral nerve roots. An anatomic investigation. Clin Orthop Relat Res (278):46-50, 1992

5. Davidson D, Rowan R, Reilly C: Lumbosacral nerve root anomaly associated with spondylolisthesis in an adolescent: a case report and review of the literature. Spine (Phila Pa 1976) 31:E718-E721, 2006

6. Garcia-Albea E, Cabrera F, Tejeiro J, Jimenez-Jimenez FJ, Vaquero A: Delayed postexertional headache, intracranial hypotension and racket sports. J Neurol Neurosurg Psychiatry 55:975, 1992

7. Gibson BE, Wedel DJ, Faust RJ, Petersen RC: Continuous epidural saline infusion for the treatment of low CSF pressure headache. Anesthesiology 68:789-791, 1988

8. Haijiao W, Koti M, Smith FW, Wardlaw D: Diagnosis of lumbosacral nerve root anomalies by magnetic resonance imaging. J Spinal Disord 14:143-149, 2001

9. Kikuchi S, Hasue M, Nishiyama K, Ito T: Anatomic and clinical studies of radicular symptoms. Spine (Phila Pa 1976) 9:23-30, 1984

10. Moayeri NN, Henson JW, Schaefer PW, Zervas NT: Spinal dural enhancement on magnetic resonance imaging associated with spontaneous intracranial hypotension. Report of three cases and review of the literature. J Neurosurg 88:912-918, 1998

11. Mokri B, Piepgras DG, Miller GM: Syndrome of orthostatic headaches and diffuse pachymeningeal gadolinium enhancement. Mayo Clin Proc 72:400-413, 1997

12. Moret F, Renaudot C, Bozon M, Castellani V: Semaphorin and neuropilin co-expression in motoneurons sets axon sensitivity to environmental semaphorin sources during motor axon pathfinding. Development 134:4491-4501, 2007

13. Neidre A, Macnab I: Anomalies of the lumbosacral nerve roots. Review of 16 cases and classification. Spine (Phila Pa 1976) 8:294-299, 1983

14. Nosik WA: Intracranial hypotension secondary to lumbar nerve sleeve tear. J Am Med Assoc 157:1110-1111, 1955

15. Postacchini F, Urso S, Ferro L: Lumbosacral nerve-root anomalies. J Bone Joint Surg Am 64:721-729, 1982

16. Raper JA: Semaphorins and their receptors in vertebrates and invertebrates. Curr Opin Neurobiol 10:88-94, 2000
17. Sanyas I, Bozon M, Moret F, Castellani V: Motoneuronal Sema3C is essential for setting stereotyped motor tract positioning in limb-derived chemotropic semaphorins. Development 139:3633-3643, 2012

18. Sato Y, Honda Y, Maruoka H, Kunoh H, Oizumi K: Subdural hematoma following disappearance of orthostatic headache and pressure normalization in two patients with spontaneous intracranial hypotension. Cephalalgia 18:60-63, 1998

19. Schievink WI: Spontaneous spinal cerebrospinal fluid leaks and intracranial hypotension. JAMA 295:2286-2296, 2006

20. Schievink WI, Ebersold MJ, Atkinson JL: Roller-coaster headache due to spinal cerebrospinal fluid leak. Lancet 347:1409, 1996

21. Schievink WI, Morreale VM, Atkinson JL, Meyer FB, Piepgras DG, Ebersold MJ: Surgical treatment of spontaneous spinal cerebrospinal fluid leaks. J Neurosurg 88:243-246, 1998

22. Schievink WI, Reimer R, Folger WN: Surgical treatment of spontaneous intracranial hypotension associated with a spinal arachnoid diverticulum. Case report. J Neurosurg 80:736-739, 1994

23. Szeinfeld M, Ihmeidan IH, Moser MM, Machado R, Klose KJ, Serafini AN: Epidural blood patch: evaluation of the volume and spread of blood injected into the epidural space. Anesthesiology 64:820-822, 1986

24. Vishteh AG, Schievink WI, Baskin JJ, Sonntag VK: Cervical bone spur presenting with spontaneous intracranial hypotension. Case report. J Neurosurg 89:483-484, 1998

25. Weitz SR, Drasner K: Spontaneous intracranial hypotension: a series. Anesthesiology 85:923-925, 1996

\section{Disclosures}

The authors report no conflict of interest concerning the materials or methods used in this study or the findings specified in this paper.

\section{Author Contributions}

Conception and design: Dahdaleh, Lopez, Arnaout, Curran. Acquisition of data: Dahdaleh, Arnaout, Shaibani. Analysis and interpretation of data: Dahdaleh, Lopez, Arnaout, Curran, Shaibani. Drafting the article: Lopez, Campbell. Critically revising the article: all authors. Reviewed submitted version of manuscript: all authors. Approved the final version of the manuscript on behalf of all authors: Dahdaleh. Study supervision: Dahdaleh.

\section{Correspondence}

Nader S. Dahdaleh, Department of Neurological Surgery, Northwestern University, Feinberg School of Medicine, 676 N St. Clair St., Ste. 2210, Chicago, IL 60611. email: nader. dahdaleh@northwestern.edu. 